Review

\title{
Immune Signaling and Antimicrobial Peptide Expression in Lepidoptera
}

\author{
Ángel M. Casanova-Torres and Heidi Goodrich-Blair * \\ Department of Bacteriology, University of Wisconsin-Madison, WI 53706, USA; \\ E-Mail: amcasanova@wisc.edu \\ * Author to whom correspondence should be addressed; E-Mail: hgblair@bact.wisc.edu; \\ Tel.: +1-608-265-4537; Fax: +1-608-262-9865.
}

Received: 1 June 2013; in revised form: 21 June 2013 / Accepted: 21 June 2013 /

Published: 2 July 2013

\begin{abstract}
Many lepidopteran insects are agricultural pests that affect stored grains, food and fiber crops. These insects have negative ecological and economic impacts since they lower crop yield, and pesticides are expensive and can have off-target effects on beneficial arthropods. A better understanding of lepidopteran immunity will aid in identifying new targets for the development of specific insect pest management compounds. A fundamental aspect of immunity, and therefore a logical target for control, is the induction of antimicrobial peptide (AMP) expression. These peptides insert into and disrupt microbial membranes, thereby promoting pathogen clearance and insect survival. Pathways leading to AMP expression have been extensively studied in the dipteran Drosophila melanogaster. However, Diptera are an important group of pollinators and pest management strategies that target their immune systems is not recommended. Recent advances have facilitated investigation of lepidopteran immunity, revealing both conserved and derived characteristics. Although the general pathways leading to AMP expression are conserved, specific components of these pathways, such as recognition proteins have diverged. In this review we highlight how such comparative immunology could aid in developing pest management strategies that are specific to agricultural insect pests.
\end{abstract}

Keywords: Lepidoptera; recognition; signaling; antimicrobial peptide; pest control 


\section{Introduction}

Lepidoptera include agricultural pests that, through feeding and other activities, negatively affect stored grains [1], food and fiber crops [2,3]. Since a single Lepidoptera adult can produce hundreds of eggs, and their primary food source is typically plant material, they can cause significant damage to agricultural crops. Although biological agents can help manage these insect pests, insecticides currently are essential for large-scale effective and economical pest control [4]. These insecticides can also affect non-target organisms, including pollinators, and their application not only disrupts natural ecosystems but also reduces yields of crops that rely on pollination [5,6]. The non-target effect of some pesticides is in part due to their effects on insect immunity, which is necessary for insect survival in natural environments. For example, currently used pesticides have been shown to affect cellular [7-10] and humoral [11,12] immune responses and interfere with grooming behavior [13,14]. These effects on immunity are likely non-specific and negatively impact the health of both the target pest and beneficial arthropods. Therefore, there is a need for novel target-specific approaches to control insect pests without affecting beneficial arthropods.

Although immune pathways can be generally and non-specifically inhibited by pesticides, they also are a likely source of candidate molecules that could be inhibited for target-specific insect control since multiple classes of insect immunity genes, including signaling pathways, can be under strong selection for diversification [15]. Fundamental mechanisms of innate immunity comprising cellular and humoral pathways are conserved throughout the animal kingdom [16] and are controlled by signaling pathways activated by various stimuli $[17,18]$, including pathogen recognition by immune surveillance systems. Despite this overall conservation, aspects of immune systems are subject to strong selection to evolve in response to varying pathogen exposure and to pathogen evolution of virulence determinants that modulate immunity [15,19-21]. Such co-evolutionary dynamics can promote diversification of conserved elements of immunity as well as the recruitment of novel effectors [22]. As such, the investigation of insect immune pathways and mechanisms of pathogen modulation can yield insights into components that may be susceptible to inhibition. For example, the insect pathogen Xenorhabdus nematophila suppresses cellular and humoral immunity in the lepidopteran moths Manduca sexta and Spodoptera exigua [23,24] but not in the dipteran fly Drosophila melanogaster [25], suggesting the stage of immunity suppressed by $X$. nematophila may be absent from $D$. melanogaster, but present in Lepidoptera. Since dipteran flies serve as pollinators [26,27], decomposers, food sources for other animals, and pest control agents, capitalizing on the possible differences between dipteran and lepidopteran immune signaling cascades will help in the identification of targets for pest-specific inhibition. With this knowledge in hand, pest management can be achieved by developing small molecule inhibitors of these targets that will suppress pest insect immunity and lead to increased susceptibility to environmental pathogens. Indeed, many insecticides may contribute to insect (target and non-target) death by modulating aspects of immunity [5]. The feasibility of targeted pest control via insect immune inhibition has been established for termites; a small molecule inhibitor of an immune surveillance protein led to faster termite death upon exposure to various pathogens [28].

Much of our current knowledge of insect immune signaling pathways and receptor and effector function is based on the premiere model organism D. melanogaster, for which there are extensive genetic tools and several fully sequenced genomes [29]. Well-established lepidopteran insect models 
such as the silkworm Bombyx mori and the tobacco hornworm M. sexta also have been widely used to study insect immunity. These organisms have been particularly useful for investigating hemolymph proteins and hemocyte function because of their relatively large larval size and hemolymph volume [16]. Many insects in the order Lepidoptera are easy to rear in laboratory conditions, and new tools such as RNA interference have been implemented successfully to study genetics of their immune systems [30,31]. Also, their immune signaling pathways are gradually being revealed by genomic and transcriptomic data [32-38]. Based on these model insect systems a fairly detailed picture of immunity, from pathogen detection to effector function, is emerging, though many gaps remain, particularly with regard to components that are unique to different insect orders. Here we review aspects of insect immunity with an emphasis on the similarities and distinctions between D. melanogaster and representative Lepidoptera.

\section{Insect Immunity}

In insects, the cellular immune response includes phagocytosis, nodulation and encapsulation [39-42] and the humoral response involves the expression of antimicrobial peptides (AMPs) $[43,44]$ as well as the pro-phenol oxidase (proPO) proteolytic cascade that results in formation of melanized nodules and toxic reactive compounds $[45,46]$. AMPs are small cationic peptides that insert into and disrupt microbial membranes, thereby killing and clearing pathogens [44]. They are synthesized by hemocytes and to a greater extent in fat body from which they are released into the insect hemolymph rapidly after microbial infection [43,47]. AMPs are also expressed in extra-embryonic tissues of eggs [48], which may help protect the developing embryo from infection.

AMPs are a conserved component of immunity in plants [49] and animals [50] and while they have diverse structures most can be assigned to larger families such as cecropins, attacins, defensins and diptericins [51]. Their diversity and immune effector function as well as their variant representation among insects (Table 1) have made them a central focus in the study of invertebrate pathology [30,52]. In D. melanogaster AMP synthesis is transcriptionally regulated through the Toll and immune deficiency (IMD) pathways. Each of these pathways is activated by detection of microbial components via different pattern recognition receptors (PRRs) that trigger, through complex regulatory cascades, nuclear factor kappa B (NF- $\mathrm{kB})$ dependent transcription of the genes encoding AMPs. After AMPs are translated in the cytoplasm they are released into the hemolymph where their high concentrations and broad activity are thought to enhance clearance of invading microorganisms from the insect [53]. Bioinformatic and experimental data support the existence of the AMP-inducing Toll and Imd pathways in lepidopterans, though not all components have been identified in model organisms such as M. sexta [32,35]. The conserved presence of AMPs in immunity coupled with the possibility that certain elements of their induction pathways may vary among insects enhances the probability that microbially-induced AMP expression could be inhibited in a pest-specific manner. As such, for the remainder of this review we focus on pathways leading to AMP gene expression. 
Table 1. Lepidoptera-specific immune effectors.

\begin{tabular}{|c|c|c|c|}
\hline Receptor/Effector & Class & \multicolumn{1}{|c|}{ Activity } & Reference \\
\hline BmPGRP-L1-L5 & PRR & \multicolumn{1}{|c|}{ Peptidoglycan recognition } & {$[54,55]$} \\
\hline BGRP1-3 & PRR & \multicolumn{1}{|c|}{$\beta$ glucan recognition } & {$[54,56,57]$} \\
\hline Hemolin & PRP & Binds LPS and LTA; triggers cellular response & {$[58,59]$} \\
\hline HP14 & PRR & Binds Lys-PGN; triggers proPO activation & {$[60]$} \\
\hline Moricin & AMP & $\begin{array}{l}\text { Antibacterial activity against Gram-positive and Gram- } \\
\text { negative bacteria; targets cytoplasmic membrane; } \\
\text { increases membrane permeability }\end{array}$ & {$[61]$} \\
\hline Gloverin & AMP & $\begin{array}{l}\text { Antimicrobial activity against fungi, and Gram-negative } \\
\text { and Gram-positive bacteria; targets outer membrane; } \\
\text { inhibition of outer membrane proteins }\end{array}$ & {$[62]$} \\
\hline Lebocin & AMP & $\begin{array}{l}\text { Antimicrobial activity against fungi, and Gram-negative } \\
\text { and Gram-positive bacteria }\end{array}$ & {$[63,64]$} \\
\hline
\end{tabular}

\section{Signaling Pathways Involved in Antimicrobial Peptide Gene Expression}

\subsection{Induction of AMP Genes by the NF-kB Family of Transcription Factors}

In D. melanogaster, transcription of AMP-encoding genes is activated by the NF- $\kappa \mathrm{B}$ family transcription factors in response to infection [65-69] with distinct NF- $\kappa$ B family transcription factors responding to the Toll and immune deficiency (IMD) signal transduction pathways [70]. In response to Toll pathway activation, the NF- $\kappa \mathrm{B}$ inhibitor Cactus is phosphorylated and degraded allowing its targets, the NF- $\kappa B$ factors Dif and Dorsal, to be translocated to the nucleus. IMD pathway activity culminates in the NF- $\mathrm{KB}$ factor Relish being activated by a stimulus-induced proteolytic cleavage [71]. In the case of Dif and Dorsal, gram-positive bacterial and fungal infections primarily serve as the stimuli that induce degradation of Cactus through the Toll signaling pathway. In general, gram-negative bacterial infections of $D$. melanogaster stimulate the proteolytic cleavage of Relish through the IMD pathway. Once in the nucleus, these transcription factors drive the transcription of immune effectors, including AMP genes whose promoters contain NF- $\kappa B$ binding sites [70,72]. Overall, NF- $\mathrm{KB}$ proteins and their DNA-binding specificities are conserved among organisms, including those Lepidoptera studied to date $[73,74]$. However, the NFKB-binding regions for Inhibitor of $\kappa \mathrm{B}(\mathrm{I} \kappa \mathrm{B})$ proteins (e.g., Cactus) are not conserved, suggesting diversification and co-adaptation

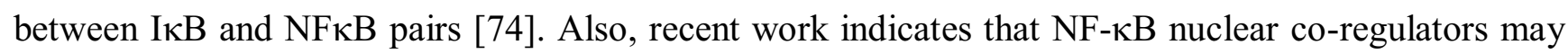
contribute to species-specific regulation of AMP gene expression [75]. Therefore, modulation of inhibitors and nuclear-co-regulators of NF- $\mathrm{BB}$-dependent transcription may be one avenue by which target-specific immune suppression could be achieved.

\subsection{Recognition and Proteolytic Cascades}

In D. melanogaster, NF-кB-dependent AMP induction through the Toll and Imd pathways is activated by detection of microbial components via different pattern recognition receptors (PRRs). PRRs are soluble or membrane-bound proteins that bind to specific microbe associated molecular patterns (MAMPs) such as lipopolysaccharide (LPS), lipoteichoic acid (LTA), peptidoglycan (PGN) or 
$\beta$-1,3-glucan that are released from or are found on the cell surfaces of bacteria or fungi [55]. Upon interaction with MAMPs, PRRs can directly agglutinate pathogens or trigger proteolytic signaling cascades and cytokine release, which in turn lead to the activation of downstream cellular and humoral pathways, including pro-PO activation and AMP gene expression $[16,65,76]$.

PGN recognition proteins (PGRPs) and $\beta$-1,3-glucanase-related proteins ( $\beta$ GRPs) were discovered in the lepidopteran silkworm (B. mori) by assaying for plasma components that activate the proPO cascade [77]. PGRPs were subsequently shown to be conserved across mammals and insects [78], and in D. melanogaster their role in the induction of AMP gene expression through Toll and IMD pathways in response to PGN has been well documented [79-83]. Similarly, $\beta$ GRPs have been shown to induce AMP expression through Toll pathway in response to fungal infections [79,84]. In contrast, there is a dearth of literature linking specific PGRPs or $\beta$ GRPs to AMP induction in Lepidoptera [85]. Such a link is possible, since PGN and $\beta$-1,3-glucan can activate AMP gene expression in M. sexta and B. mori [85-90] and multiple infection-induced PGRP- and $\beta$ GRP-encoding genes have been identified in Lepidoptera [32,38,54,55,91-94]. However, there are numerous hints that Lepidoptera and Diptera may have evolved divergent mechanisms of linking pathogen detection to conserved Toll and IMD signal transduction cascades. First, a genome comparison between B. mori and D. melanogaster failed to identify 1:1 PGRP orthologs [54]. Similarly, B. mori gram-negative binding protein (GNBP) and M. sexta microbe binding protein (MBP), members of the $\beta$-1,3-glucanase-related protein superfamily [76,95], appear to be distantly related to D. melanogaster GNBPs [76], suggesting divergence of this group of proteins. M. sexta MBP expression is strongly up-regulated in fat body after immune challenge and shows specific binding to LTA, LPS, DAP-PGN [76]. Also, in contrast to the situation in D. melanogaster, highly purified LPS and LTA are inducers of AMP gene expression in Lepidoptera, though not as potently as crude LPS (with contaminating PGN) or purified PGN $[85,90,96,97]$. This raises the possibility that different MAMPs or combinations of MAMPs are most efficacious in eliciting AMP gene expression in Lepidoptera relative to Diptera. Also, since purified LPS can elicit AMP expression in Lepidoptera but not D. melanogaster, Lepidoptera have either a distinct repertoire of PRRs responsible for LPS-dependent triggering of Imd or Toll pathways, or an as-yet undiscovered pathway that links LPS to AMP induction. Testing these ideas awaits the identification of the suite of PRRs and signal transduction pathways responsible for transducing LPS, LTA, PGN, or combinatorial microbial signals to AMP gene expression.

One class of lepidopteran PRR that may mediate infection-dependent induction of AMPs is the C-type lectins (CTLs), $\mathrm{Ca}^{2+}$-dependent, secreted proteins that have carbohydrate-binding capabilities. Lepidopteran CTLs are involved in immunity. Similar to some CTLs of D. melanogaster [98], several CTLs of M. sexta [55] and B. mori [54,99] are reported to mediate induction of cellular responses and the proPO cascade. Although the nomenclature quickly becomes confusing, CTLs include lipopolysaccharide-binding protein (LBP). B. mori LBP binds LPS and triggers cellular responses (nodulation) [100]. Finally, immulectins (IML) are also CTLs. M. sexta IML-1 binds to Gram-positive and Gram-negative bacteria as well as yeast [101], IML-2 shows specific binding to LPS [102], IML-3 and IML-4 show specific binding to LPS and LTA, and IML-3 can also bind laminarin, a $3-1,3$-glucan $[103,104]$. Diversity in CTL carbohydrate-binding specificities may result in lineage-specific pathogen recognition-signal transduction connections. 
Of particular relevance to the theme of this review are PRRs present in Lepidoptera but not Diptera (Table 1). In general, both orders of insects encode $\beta$ GRPs and PGRPs. However, specific representatives of each class are restricted to Lepidoptera (Table 1). For example, the Lepidopteran $\beta$ GRP-2, which binds fungal cell wall $\beta-1,3$ glucans [55] and LTA [105], is absent from Diptera [54]. Such derived $\beta$ GRP and PGRPs may contribute to lepidopteran-specific transduction of signals to downstream pathways. Other Lepidoptera-specific PRRs are hemolin and hemolymph proteinase-14 precursor (proHP14) (Table 1). Like IML C-type lectins, hemolin is an LPS- and LTA-binding PRR [58] with roles in mediating cellular responses and as an opsonin to enhance phagocytosis [59]. HP14 has been shown to detect and bind a broad range of MAMPs, and may coordinate with $\beta$ GRP1 or $\beta$ GRP2 to activate proPO $[60,106]$. The potential role of the PRRs discussed above in mediating the expression of AMP genes remains to be determined, and further study of the Lepidoptera-specific immune surveillance proteins and divergent activities of conserved PRRs likely will yield novel avenues for pest-control.

\subsection{Toll Pathway}

D. melanogaster has both MAMP-dependent and MAMP-independent routes to activate the Toll pathway [107]. In MAMP-dependent Toll induction, bacterial Lys-PGN (typical of gram-positive bacteria) is detected by PGRP-SA or PGRP-SD (in the presence of GNBP-1), while yeast or fungal $\beta$-1,3-glucan is detected by GNBP-3 [85,108,109] (Figure 1). MAMP-independent stimuli are virulence determinants, such as proteases and chitinases, secreted by microbes and dubbed "danger signals" [110]. MAMPs and MAMP-independent stimuli each trigger a distinct proteolytic cascade [111] that both culminate in cleavage of the cytokine Spätzle by the serine protease Spätzle processing enzyme (SPE) [112]. Interaction of active Spätzle C-terminal domain (C-106) with the surface-localized Toll receptor triggers an intracellular signal transduction terminating in induced expression of AMPs and cellular responses [113].

Some of the basic components of the Toll pathway are present in Lepidoptera (Figure 2). M. sexta hemocytes express an infection-induced Toll-like receptor and the genome of B. mori encodes 14 genes predicted to encode Toll-like receptors as well as homologs of each of the intracellular components of Toll-dependent signaling [85,114,115]. Both M. sexta and B. mori encode homologs of the D. melanogaster Toll-activating cytokine Spätzle [116] (Figure 2). Also, for both M. sexta and B. mori there is experimental evidence linking the Toll pathway with AMP induction [116-118]. In M. sexta, Toll pathway results in expression of several antimicrobial peptides, including attacin-1, cecropin-6, moricin and lysozyme. In addition, the transcript level of hemolin, a pattern recognition protein exclusive to lepidopterans (Table 1), is induced by injection of activated Spätzle-C108 into larvae [116].

Despite the conservation of certain aspects of the Toll pathway, the extracellular cascades that lead to Spätzle activation may have diverged between D. melanogaster and the two Lepidoptera (Figure 1). For example, in contrast to what is known in D. melanogaster, the M. sexta Toll pathway is activated by gram-negative-associated MAMPs [115,118]. Also, the genome of $B$. mori lacks 1:1 orthologs of Grass, Spirit and Persephone [54], the D. melanogaster serine proteases responsible for MAMP/PRRdependent and MAMP-independent cleavage of SPE (Figure 1). Progress has been made in identifying 
a $M$. sexta proteolytic cascade that results in processing pro-Spätzle into its active C-terminal domain (C-108). The direct cleavage is mediated by hemolymph proteinase (HP) $8[11,13]$, a homolog of D. melanogaster SPE [119], In turn, HP8 is processed into its active form by HP6. HP6 is most similar to D. melanogaster Persephone protease, which activates SPE in response to MAMP-independent stimuli [110,113]. This hemolymph proteinase is activated in response to Gram-positive or Gram-negative bacteria and in response to $\beta$-1,3-glucan [119]. However, the PRRs and proteolytic cascade that transduce MAMP signals to AMP induction are unknown (Figure 1).

Figure 1. Toll-activating signal transduction pathways in D. melanogaster and Manduca sexta. (A) The D. melanogaster Toll pathway based on the revised model presented in Ashok 2009 [107]. MAMP/PRR-dependent or a MAMP-independent danger signal cascades can both activate Toll. (B) Current knowledge of the M. sexta Toll pathway. The M. sexta Toll pathway can be activated by MAMPs, but the specific PRRs and proteolytic cascade(s) responsible for this activation have not been reported. Known components of Spätzle-activation include the proteases HP6 and HP8, which are most closely related to the danger-pathway proteases of D. melanogaster. However, the induction of the Toll pathway by MAMP-independent signals has not been documented yet in M. sexta. Dashed lines indicate potential pathways that have not been experimentally proven in M. sexta. Orange boxes represent key differences between D. melanogaster and M. sexta Toll pathway; a red border highlights proteins or pathways not yet identified in M. sexta. Boxes with same color are for putative orthologous steps. PGRP, peptidoglycan recognition protein; GNBP, gram negative binding protein; SPE, Spätzle processing enzyme; HP, hemolymph proteinase.

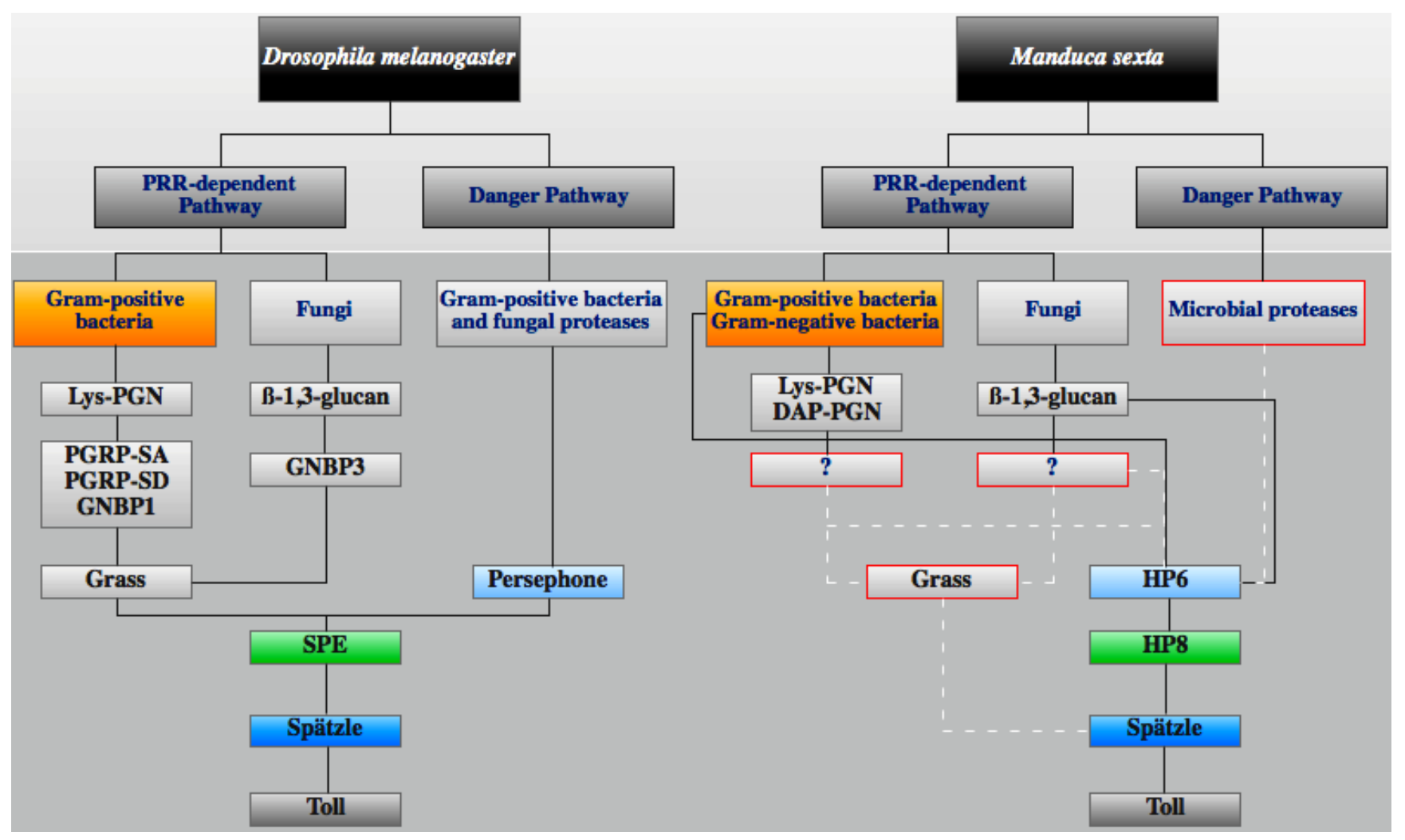


Figure 2. Phylogenetic relationships among serine proteases involved in Toll pathway activation. Sequence alignment and tree construction were performed using the amino acid sequence of D. melanogaster (Dm) Grass (Q86PB3), SPE (NP_651168.1), Persephone (Q9VWU1) and Spätzle (NP_524526.1); M. sexta (Ms) HP6 (AAV91004.1), HP8 (AAV91006.1) and Spätzle (ACU68553.1); and B. mori (Bm) fcaL22M01 (AK384444), BAEE (H9J6N1), and Spätzle (NM_001114594). Bm serine proteases were identified by TBLASTN [120] analysis the Bm genome for homologs of Ms serine proteases. The roles of these Bm proteins in Toll pathway activation have not been shown experimentally. One thousand bootstrap repetitions were performed to estimate the reliability of the tree; the percent values obtained are indicated on the nodes. Sequence alignment was performed using Clustal Omega [121,122] bootstrapping analysis, matrix calculation, matrix transformation were conducted by the Fitch-Margoliash method and the combination of the 1,000 resulting trees was identified using the Seqboot, Protdist, Fitch and Consense programs within the Phylip phylogenetic analysis package [123]. The phylogenetic tree was constructed using Phylodendron software version 0.8d, by D.G. Gilbert [124]. The phylogenetic relationships observed are consistent with those previously published [116,119]. Colored boxes for each protein match those presented in Figure 1.

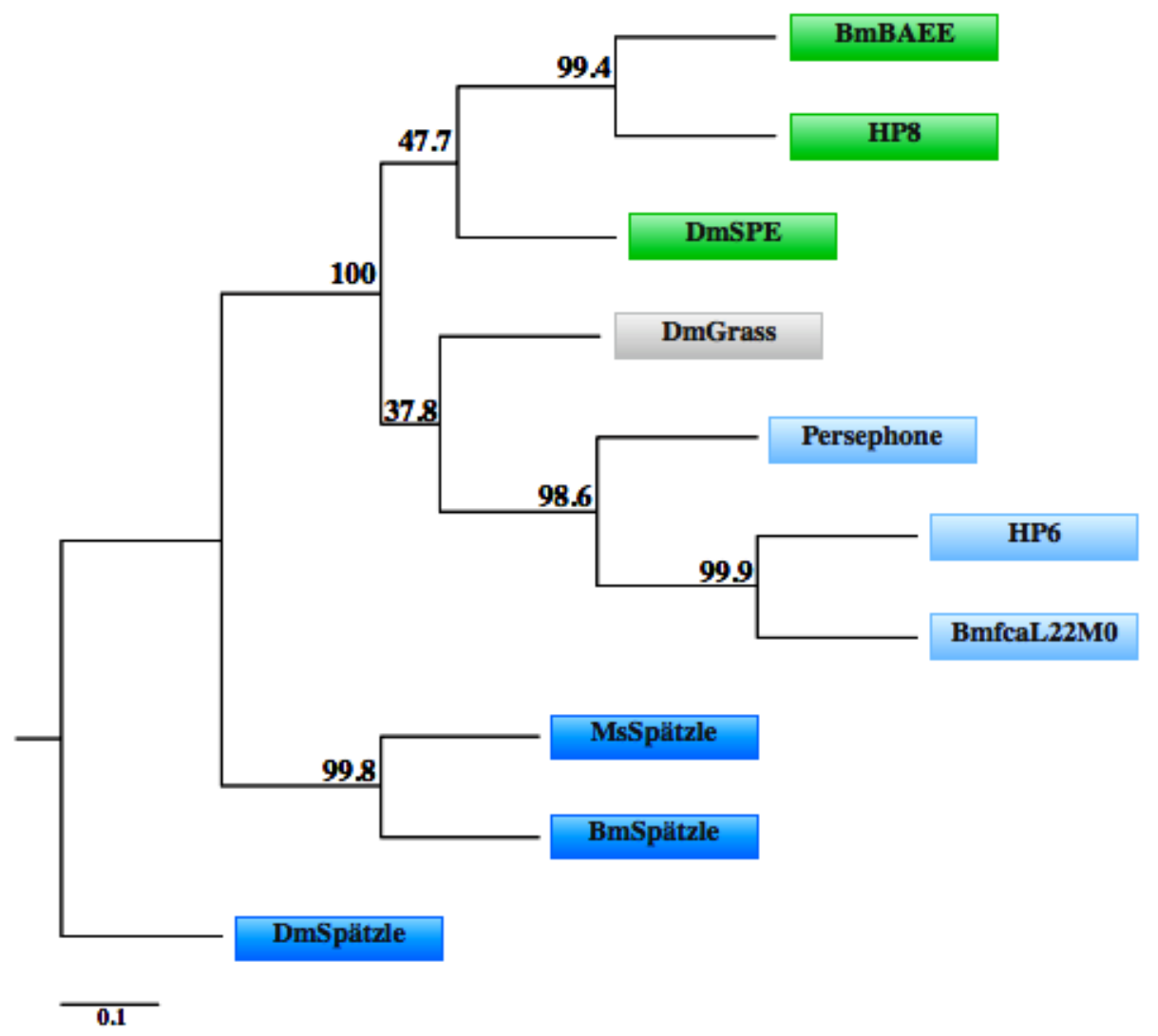

The findings reviewed above demonstrate that while the overall architecture of the Toll pathway is conserved among insects, the specific identities of proteolytic cascade members are distinct and many gaps remain in our understanding of Toll activation in Lepidoptera. Filling these gaps should reveal potential lineage-specific molecules that can serve as targets to hinder the activation of the Toll pathway in agricultural pests. 


\subsection{IMD Pathway}

In D. melanogaster the IMD pathway also contributes to AMP gene induction and is triggered by direct interaction of DAP-PGN, a MAMP typical of gram-negative bacteria, with the transmembrane receptor PGRP-LC $[82,83,125,126]$. Other members of the PGRP family also play a role upstream of IMD. For example, PGRP-LE can act as an intracellular receptor for monomeric PGN [127] and its truncated form can enhance PGRP-LC-mediated recognition [128]. DAP-PGN/PGRP-LC interaction activates intracellular IMD, which then recruits FAS-associated death domain (FADD) and death-related ced-3/Nedd2-like protein (Dredd) to form a complex [129,130]. Current evidence supports the idea that Dredd, a caspase-like molecule, cleaves the NF- $\mathrm{BB}$ transcription factor Relish [131]. Imd also appears to activate a phosphorelay: the transforming growth factor- $\beta$ (TGF $\beta$ )-activated kinase 1 (TAK1) phosphorylates the IkB kinase (IKK) "signalosome", which in turn phosphorylates Relish and contributes to its cleavage [131]. Relish cleavage into its activated amino-terminal transcriptional regulator domain allows its translocation into the nucleus, where it activates AMP gene expression [71]. The translocation of Relish into the nucleus is regulated by two recently discovered components of this pathway: inhibitor of apoptosis 2 (Iap2) and transforming growth factor-activated kinase 1 (TAK1)-binding protein 2 (Tab2) [132,133]. Both, Iap2 and Tab2 act upstream of Relish and downstream of IMD, while Iap2 functions downstream of TAK1 [132,134]. Of particular importance to AMP gene expression is Iap2, the knockdown of which hampers the sustained expression of AMP genes [135]. While Iap2 and Tab2 are necessary for Imd signal transduction, the gene product of pirk, a recently characterized gene, interacts directly with IMD and PGRP-LC. Pirk overexpression analyses revealed that it acts as a negative regulator by reducing the expression of the AMP genes attacin $\mathrm{B}$, cecropin B, and diptericin B, which are all under the control of the Imd pathway [136].

Most of the information available about the Imd pathway in Lepidoptera comes from bioinformatics; orthologs of all intracellular components of the Imd pathway have been found in B. mori [54,137] and M. sexta [35]. However, few experiments have been done to characterize the molecular mechanisms leading to activation of the Imd pathway in these insects. In $M$. sexta several genes of the Imd pathway, including those encoding IMD, FADD, TAK1, Dredd and Relish are up regulated in fat body of immune challenged 5th instar larvae [35] and in the midgut of B. mori during the wandering stage [36]. Genes encoding lysozyme, moricin and defensin AMPs also were up regulated in the midgut of $B$. mori in the wandering stage [36], consistent with the possibility that AMP induction is IMD-mediated. Finally, in the lepidopteran beet armyworm Spodoptera exigua, RNAi-mediated knockdown of Relish expression resulted in loss of cecropin induction upon fungal infection [138], further strengthening the idea that the IMD pathway may contribute to AMP gene expression in Lepidoptera, though perhaps it is triggered by distinct signals. Further study is needed to elucidate IMD-mediated AMP induction in Lepidoptera and to reveal any differences there are in this pathway between Diptera and Lepidoptera.

\section{Conclusions}

Insecticides are necessary to guarantee effective insect pest management in agricultural settings. However, the cost and off-target effects of these insecticides directly and indirectly increase economic 
burden; the latter by affecting beneficial arthropods such as pollinators. The study of insect immunity can provide tools for the development of target-specific cost-effective approaches to control agricultural pests. Directed suppression of pest immune defenses is predicted to render them susceptible to environmental and applied biocontrol pathogens, as recently demonstrated in termites by Bulmer and colleagues [28]. The studies summarized above suggest that many aspects of insect immunity, including recognition factors and serine proteases, have diverged between $D$. melanogaster and Lepidoptera. Continued comparative immunity of a broad array of species from Diptera, Lepidoptera, and other insect orders will reveal possible candidate immunity factors for target-specific approaches that will enable the effective control of insect pests. However, before such approaches can be realized, the details of lepidopteran immune signaling pathways must be elucidated. The relatively large sizes of last instar larvae of many lepidopteran species will facilitate biochemical approaches to such studies, while the establishment of immune-inducible lepidopteran cell lines such as the UGA-CiE1 cell line [139] can enable the characterization of molecular mechanisms leading to Imd pathway activation and its contribution to AMP gene expression. Finally, ongoing investigations into the immune-modulatory mechanisms of entomopathogens will help identify key steps in immunity that are susceptible to manipulation, contributing to the development of natural, cost-effective, non-toxic alternatives to chemical insecticides currently used for pest management.

\section{Acknowledgments}

Funding sources: The Goodrich-Blair lab was supported by funding from the UW-Madison USDA Hatch Multi-state research formula fund WIS01582. ACT was supported by NIH National Research Service Award T32 GM07215.

\section{References}

1. Mohandass, S.; Arthur, F.H.; Zhu, K.Y.; Throne, J.E. Biology and management of Plodia interpunctella (Lepidoptera: Pyralidae) in stored products. J. Stored Prod. Res. 2007, 43, 302-311.

2. Nègre, V.; Hôtelier, T.; Volkoff, A.-N.; Gimenez, S.; Cousserans, F.; Mita, K.; Sabau, X.; Rocher, J.; López-Ferber, M.; D’Alençon, E.; et al. SPODOBASE: An EST database for the lepidopteran crop pest Spodoptera. BMC Bioinformatics 2006, 7, 322.

3. Vail, P.V.; Hoffman, D.F.; Tebbets, J.S. Effects of a fluorescent brightener on the activity of Anagrapha falcifera (Lepidoptera: Noctuidae) nuclear Polyhedrosis virus to four Noctuid pests. Biolog. Contr. 1996, 125, 121-125.

4. Cordero, R.J.; Kuhar, T.P.; Speese, J.; Youngman, R.; Lewis, E.; Boomquist, J.; Kok, L.T.; Bratsch, A. Field efficacy of insecticides for control of lepidopteran pests on collards in Virginia. Plant Health Progr. 2006, doi:10.1094/PHP-2006-0105-01-RS.

5. James, R.R.; Xu, J. Mechanisms by which pesticides affect insect immunity. J. Invertebr. Pathol. 2012, 109, 175-182.

6. Desneux, N.; Decourtye, A.; Delpuech, J.-M. The sublethal effects of pesticides on beneficial arthropods. Annu. Rev. Entomol. 2007, 52, 81-106. 
7. Zibaee, A.; Bandani, A.R. Effects of Artemisia annua L. (Asteracea) on the digestive enzymatic profiles and the cellular immune reactions of the Sunn pest, Eurygaster integriceps (Heteroptera: Scutellaridae), against Beauveria bassiana. Bull. Entomol. Res. 2010, 100, 185-196.

8. Azambuja, P.; Garcia, E.S.; Ratcliffe, N.A.; Warthen, D.J. Immune-depression in Rhodnius prolixus induced by the growth inhibitor, azadirachtin. J. Insect Physiol. 1991, 37, 771-777.

9. Franssens, V.; Smagghe, G.; Simonet, G.; Claeys, I.; Breugelmans, B.; De Loof, A.; Vanden Broeck, J. 20-Hydroxyecdysone and juvenile hormone regulate the laminarin-induced nodulation reaction in larvae of the flesh fly, Neobellieria bullata. Dev. Comp. Immunol. 2006, 30, 735-740.

10. Delpuech, J.-M.; Frey, F.; Carton, Y. Action of insecticides on the cellular immune reaction of Drosophila melanogaster against the parasitoid Leptopilina boulardi. Environ. Toxicol. Chem. 1996, 15, 2267-2271.

11. Babu, S.R.; Subrahmanyam, B. Bio-potency of serine proteinase inhibitors from Acacia senegal seeds on digestive proteinases, larval growth and development of Helicoverpa armigera (Hübner). Pestic. Biochem. Physiol. 2010, 98, 349-358.

12. Nasr, H.M.; Badawy, M.E.I.; Rabea, E.I. Toxicity and biochemical study of two insect growth regulators, buprofezin and pyriproxyfen, on cotton leafworm Spodoptera littoralis. Pestic. Biochem. Physiol. 2010, 98, 198-205.

13. Quintela, E.D.; McCoy, C. Pathogenicity enhancement of Metarhizium anisopliae and Beauveria bassiana to first instars of Diaprepes abbreviatus (Coleoptera: Curculionidae) with sublethal doses of imidacloprid. Environ. Entomol. 1997, 26, 1173-1182.

14. Koppenhöfer, A.M.; Grewal, P.S.; Kaya, H.K. Synergism of imidacloprid and entomopathogenic nematodes against white grubs: The mechanism. Entomol. Exp. Appl. 2000, 94, 283-293.

15. Lazzaro, B.P. Natural selection on the Drosophila antimicrobial immune system. Curr. Opin. Microbiol. 2008, 11, 284-289.

16. Kanost, M.R.; Jiang, H.; Yu, X.-Q. Innate immune responses of a lepidopteran insect, Manduca sexta. Immunol. Rev. 2004, 198, 97-105.

17. Lavine, M.D.; Strand, M.R. Insect hemocytes and their role in immunity. Insect Biochem. Mol. Biol. 2002, 32, 1295-1309.

18. Marmaras, V.J.; Lampropoulou, M. Regulators and signalling in insect haemocyte immunity. Cell. Signal. 2009, 21, 186-195.

19. Jiggins, F.M.; Kim, K.W. A screen for immunity genes evolving under positive selection in Drosophila. J. Evol. Biol. 2007, 20, 965-970.

20. Sackton, T.B.; Lazzaro, B.P.; Schlenke, T.A.; Evans, J.D.; Hultmark, D.; Clark, A.G. Dynamic evolution of the innate immune system in Drosophila. Nat. Genet. 2007, 39, 1461-1468.

21. Keebaugh, E.S.; Schlenke, T.A. Adaptive evolution of a novel Drosophila lectin induced by parasitic wasp attack. Mol. Biol. Evol. 2012, 29, 565-577.

22. Sackton, T.B.; Clark, A.G. Comparative profiling of the transcriptional response to infection in two species of Drosophila by short-read cDNA sequencing. BMC Genomics 2009, 10, 259-275.

23. Park, Y.; Herbert, E.E.; Cowles, C.E.; Cowles, K.N.; Menard, M.L.; Orchard, S.S.; GoodrichBlair, H. Clonal variation in Xenorhabdus nematophila virulence and suppression of Manduca sexta immunity. Cell. Microbiol. 2007, 9, 645-656. 
24. Ji, D.; Kim, Y. An entomopathogenic bacterium, Xenorhabdus nematophila, inhibits the expression of an antibacterial peptide, cecropin, of the beet armyworm, Spodoptera exigua. J. Insect Physiol. 2004, 50, 489-496.

25. Aymeric, J.-L.; Givaudan, A.; Duvic, B. Imd pathway is involved in the interaction of Drosophila melanogaster with the entomopathogenic bacteria, Xenorhabdus nematophila and Photorhabdus luminescens. Mol. Immunol. 2010, 47, 2342-2348.

26. Kearns, C.A. North American dipteran pollinators: Assessing their value and conservation status. Conserv. Ecol. 2001, 5, 1-10.

27. Ssymank, A.; Kearns, C.A.; Pape, T.; Thompson, C. Pollinating flies (Diptera): A major contribution to plant diversity and agricultural production. Biodiversity 2007, 9, 86-89.

28. Bulmer, M.S.; Bachelet, I.; Raman, R.; Rosengaus, R.B.; Sasisekharan, R. Targeting an antimicrobial effector function in insect immunity as a pest control strategy. Proc. Natl. Acad. Sci. USA 2009, 106, 12652-12657.

29. Clark, A.G.; Eisen, M.B.; Smith, D.R.; Bergman, C.M.; Oliver, B.; Markow, T.A.; Kaufman, T.C.; Kellis, M.; Gelbart, W.; Iyer, V.N.; et al. Evolution of genes and genomes on the Drosophila phylogeny. Nature 2007, 450, 203-218.

30. Eleftherianos, I.; Millichap, P.J.; Ffrench-Constant, R.H.; Reynolds, S.E. RNAi suppression of recognition protein mediated immune responses in the tobacco hornworm Manduca sexta causes increased susceptibility to the insect pathogen Photorhabdus. Dev. Comp. Immunol. 2006, 30, 1099-1107.

31. Huvenne, H.; Smagghe, G. Mechanisms of dsRNA uptake in insects and potential of RNAi for pest control: A review. J. Insect Physiol. 2010, 56, 227-235.

32. Zhang, S.; Gunaratna, R.T.; Zhang, X.; Najar, F.; Wang, Y.; Roe, B.; Jiang, H. Pyrosequencingbased expression profiling and identification of differentially regulated genes from Manduca sexta, a lepidopteran model insect. Insect Biochem. Mol. Biol. 2011, 41, 733-746.

33. International, T.; Genome, S. The genome of a lepidopteran model insect, the silkworm Bombyx mori. Insect Biochem. Mol. Biol. 2008, 38, 1036-1045.

34. Tobacco Hornworm Genome Project. Available online: http://www.hgsc.bcm.tmc.edu/content/ tobacco-hornworm-genome-project (accessed on 6 May 2013).

35. Gunaratna, R.T.; Jiang, H. A comprehensive analysis of the Manduca sexta immunotranscriptome. Dev. Comp. Immunol. 2013, 39, 388-398.

36. Xu, Q.; Lu, A.; Xiao, G.; Yang, B.; Zhang, J.; Li, X.; Guan, J.; Shao, Q.; Beerntsen, B.T.; Zhang, P.; et al. Transcriptional profiling of midgut immunity response and degeneration in the wandering silkworm, Bombyx mori. PLoS One 2012, 7, 1-14.

37. Pauchet, Y.; Wilkinson, P.; Vogel, H.; Nelson, D.R.; Reynolds, S.E.; Heckel, D.G.; FfrenchConstant, R.H. Pyrosequencing the Manduca sexta larval midgut transcriptome: Messages for digestion, detoxification and defence. Insect Mol. Biol. 2010, 19, 61-75.

38. Zou, Z.; Najar, F.; Wang, Y.; Roe, B.; Jiang, H. Pyrosequence analysis of expressed sequence tags for Manduca sexta hemolymph proteins involved in immune responses. Insect Biochem. Mol. Biol. 2008, 38, 677-682.

39. Schmidt, O.; Theopold, U.; Strand, M. Innate immunity and its evasion and suppression by hymenopteran endoparasitoids. Bioessays 2001, 23, 344-351. 
40. Nappi, A.J.; Kohler, L.; Mastore, M.; Funzionale, B. Signaling pathways implicated in the cellular innate immune responses of Drosophila. Invertebrate Surviv. J. 2004, 1, 5-33.

41. Lamprou, I.; Tsakas, S.; Theodorou, G.L.; Karakantza, M.; Lampropoulou, M.; Marmaras, V.J. Uptake of LPS/E. coli/latex beads via distinct signalling pathways in medfly hemocytes: The role of MAP kinases activation and protein secretion. Biochim. Biophys. Acta 2005, 1744, 1-10.

42. Sideri, M.; Tsakas, S.; Markoutsa, E.; Lampropoulou, M.; Marmaras, V.J. Innate immunity in insects: Surface-associated dopa decarboxylase-dependent pathways regulate phagocytosis, nodulation and melanization in medfly haemocytes. Immunology 2008, 123, 528-537.

43. Bulet, P.; Hetru, C.; Dimarcq, J.L.; Hoffmann, D. Antimicrobial peptides in insects; structure and function. Dev. Comp. Immunol. 1999, 23, 329-344.

44. Bulet, P.; Stöcklin, R. Insect antimicrobial peptides: Structures, properties and gene regulation. Protein Pept. Lett. 2005, 12, 3-11.

45. González-Santoyo, I.; Córdoba-Aguilar, A. Phenoloxidase: A key component of the insect immune system. Entomol. Exp. Appl. 2012, 142, 1-16.

46. Zhao, P.; Li, J.; Wang, Y.; Jiang, H. Broad-spectrum antimicrobial activity of the reactive compounds generated in vitro by Manduca sexta phenoloxidase. Insect Biochem. Mol. Biol. 2007, 37, 952-959.

47. Hoffmann, J.A. Phylogenetic perspectives in innate immunity. Science 1999, 284, 1313-1318.

48. Gorman, M.J.; Kankanala, P.; Kanost, M.R. Bacterial challenge stimulates innate immune responses in extra-embryonic tissues of tobacco hornworm eggs. Insect Mol. Biol. 2004, 13, $19-24$.

49. García-Olmedo, F.; Molina, A.; Alamillo, J.M.; Rodríguez-Palenzuéla, P. Plant defense peptides. Biopolymers 1998, 47, 479-491.

50. Zasloff, M. Antimicrobial peptides of multicellular organisms. Nature 2002, 415, 389-395.

51. Ravi, C.; Jeyashree, A.; Renuka Devi, K. Antimicrobial peptides from insects: An overview. Res. Biotech. 2011, 2, 1-7.

52. Haine, E.R.; Moret, Y.; Siva-Jothy, M.T.; Rolff, J. Antimicrobial defense and persistent infection in insects. Science 2008, 322, 1257-1259.

53. Meister, M.; Lemaitre, B.; Hoffmann, J.A. Antimicrobial peptide defense in Drosophila. BioEssays 1997, 19, 1019-1026.

54. Tanaka, H.; Ishibashi, J.; Fujita, K.; Nakajima, Y.; Sagisaka, A.; Tomimoto, K.; Suzuki, N.; Yoshiyama, M.; Kaneko, Y.; Iwasaki, T.; et al. A genome-wide analysis of genes and gene families involved in innate immunity of Bombyx mori. Insect Biochem. Mol. Biol. 2008, 38, 1087-1110.

55. Yu, X.-Q.; Zhu, Y.-F.; Ma, C.; Fabrick, J.A.; Kanost, M.R. Pattern recognition proteins in Manduca sexta plasma. Insect Biochem. Mol. Biol. 2002, 32, 1287-1293.

56. Ma, C.; Kanost, M.R. A $\beta$-1,3-glucan recognition protein from an insect, Manduca sexta, agglutinates microorganisms and activates the phenoloxidase cascade. J. Biol. Chem. 2000, 275, $7505-7514$.

57. Fabrick, J.A.; Baker, J.E.; Kanost, M.R. cDNA cloning, purification, properties, and function of a $\beta$-1,3-glucan recognition protein from a pyralid moth, Plodia interpunctella. Insect Biochem. Mol. Biol. 2003, 33, 579-594. 
58. Yu, X.; Kanost, M.R. Binding of hemolin to bacterial lipopolysaccharide and lipoteichoic acid: An immunoglobulin superfamily member from insects as a pattern-recognition receptor. Eur. J. Biochem. 2002, 1834, 1827-1834.

59. Eleftherianos, I.; Gökçen, F.; Felföldi, G.; Millichap, P.J.; Trenczek, T.E.; Ffrench-Constant, R.H.; Reynolds, S.E. The immunoglobulin family protein Hemolin mediates cellular immune responses to bacteria in the insect Manduca sexta. Cell. Microbiol. 2007, 9, 1137-1147.

60. Ji, C.; Wang, Y.; Guo, X.; Hartson, S.; Jiang, H. A pattern recognition serine proteinase triggers the prophenoloxidase activation cascade in the tobacco hornworm, Manduca sexta. J. Biol. Chem. 2004, 279, 34101-34106.

61. Hara, S.; Yamakawa, M. Moricin, a novel type of antibacterial peptide isolated from the silkworm, Bombyx mori. J. Biol. Chem. 1995, 270, 29923-29927.

62. Xu, X.-X.; Zhong, X.; Yi, H.-Y.; Yu, X.-Q. Manduca sexta gloverin binds microbial components and is active against bacteria and fungi. Dev. Comp. Immunol. 2012, 38, 275-284.

63. Chowdhury, S.; Taniai, K.; Hara, S.; Kadono-Okuda, K.; Kato, Y.; Yamamoto, M.; Xu, J.; Su Kyung, C.; Debnath, N.C.; Choi, H.K.; et al. cDNA cloning and gene expression of lebocin, a novel member of antibacterial peptides from the silkworm, Bombyx mori. Biochem. Biophys. Res. Commun. 1995, 214, 271-278.

64. Rao, X.-J.; Xu, X.-X.; Yu, X.-Q. Functional analysis of two lebocin-related proteins from Manduca sexta. Insect Biochem. Mol. Biol. 2012, 42, 231-239.

65. Hoffmann, J.A. The immune response of Drosophila. Nature 2003, 426, 33-38.

66. Lemaitre, B.; Hoffmann, J.A. The host defense of Drosophila melanogaster. Annu. Rev. Immunol. 2007, 25, 697-743.

67. Ip, Y.T.; Reach, M.; Engstrom, Y.; Kadalayil, L.; Cai, H.; González-Crespo, S.; Tatei, K.; Levine, M. Dif, a dorsal-related gene that mediates an immune response in Drosophila. Cell 1993, 75, 753-763.

68. Dushay, M.S.; Asling, B.; Hultmark, D. Origins of immunity: Relish, a compound Rel-like gene in the antibacterial defense of Drosophila. Proc. Natl. Acad. Sci. USA 1996, 93, 10343-10347.

69. Hedengren, M.; Asling, B.; Dushay, M.S.; Ando, I.; Ekengren, S.; Wihlborg, M.; Hultmark, D. Relish, a central factor in the control of humoral but not cellular immunity in Drosophila. Mol. Cell 1999, 4, 827-837.

70. Engstrom, Y.; Kadalayil, L.; Sun, S.-C.; Samakovlis, C.; Hultmark, D.; Faye, I. kB-like motifs regulate the induction of immune genes in Drosophila. J. Mol. Biol. 1993, 232, 327-333.

71. Stöven, S.; Ando, I.; Kadalayil, L.; Engström, Y.; Hultmark, D. Activation of the Drosophila NF-kappaB factor Relish by rapid endoproteolytic cleavage. EMBO Rep. 2000, 1, 347-352.

72. Kappler, C.; Meister, M.; Lagueux, M.; Gateff, E.; Hoffmann, J.A.; Reichhart, J. Insect immunity. Two $17 \mathrm{bp}$ repeats nesting a kB-related sequence confer inducibility to the diptericin gene and bind a polypeptide in bacteria-challenge Drosophila. EMBO J. 1993, 12, 1561-1568.

73. Ghosh, S.; May, M.J.; Kopp, E.B. NF-kappa B and Rel proteins: Evolutionarily conserved mediators of immune responses. Annu. Rev. Immunol. 1998, 16, 225-260.

74. Ryzhakov, G.; Teixeira, A.; Saliba, D.; Blazek, K.; Muta, T.; Ragoussis, J.; Udalova, I.A. Crossspecies analysis reveals evolving and conserved features of the NF-kB proteins. J. Biol. Chem. 2013, 288, 11546-11554. 
75. Rao, X.-J.; Xu, X.-X.; Yu, X.-Q. Manduca sexta moricin promoter elements can increase promoter activities of Drosophila melanogaster antimicrobial peptide genes. Insect Biochem. Mol. Biol. 2011, 41, 982-992.

76. Wang, Y.; Sumathipala, N.; Rayaprolu, S.; Jiang, H. Recognition of microbial molecular patterns and stimulation of prophenoloxidase activation by a $\beta$-1,3-glucanase-related protein in Manduca sexta larval plasma. Insect Biochem. Mol. Biol. 2011, 41, 322-331.

77. Yoshida, H.; Ochiai, M.; Ashida, M. ß-1,3-glucan receptor and peptidoglycan receptor are present as separate entities within insect prophenoloxidase activating system. Biochem. Biophys. Res. Commun. 1986, 141, 1177-1184.

78. Kang, D.; Liu, G.; Lundström, A.; Gelius, E.; Steiner, H. A peptidoglycan recognition protein in innate immunity conserved from insects to humans. Proc. Natl. Acad. Sci. USA 1998, 95, 10078-10082.

79. Ferrandon, D.; Imler, J.-L.; Hoffmann, J.A. Sensing infection in Drosophila: Toll and beyond. Semin. Immunol. 2004, 16, 43-53.

80. Choe, K.-M.; Werner, T.; Stöven, S.; Hultmark, D.; Anderson, K.V. Requirement for a peptidoglycan recognition protein (PGRP) in Relish activation and antibacterial immune responses in Drosophila. Science 2002, 296, 359-362.

81. Takehana, A.; Katsuyama, T.; Yano, T.; Oshima, Y.; Takada, H.; Aigaki, T.; Kurata, S. Overexpression of a pattern-recognition receptor, peptidoglycan-recognition protein-LE, activates imd/relish-mediated antibacterial defense and the prophenoloxidase cascade in Drosophila larvae. Proc. Natl. Acad. Sci. USA 2002, 99, 13705-13710.

82. Gottar, M.; Gobert, V.; Michel, T.; Belvin, M.; Duyk, G.; Hoffmann, J.A.; Ferrandon, D.; Royet, J. The Drosophila immune response against Gram-negative bacteria is mediated by a peptidoglycan recognition protein. Nature 2002, 416, 640-644.

83. Rämet, M.; Manfruelli, P.; Pearson, A.; Mathey-Prevot, B.; Ezekowitz, R.A.B. Functional genomic analysis of phagocytosis and identification of a Drosophila receptor for E. coli. Nature 2002, 416, 644-648.

84. Gottar, M.; Gobert, V.; Matskevich, A.A.; Reichhart, J.M.; Wang, C.; Butt, T.M.; Belvin, M.; Hoffmann, J.A.; Ferrandon, D. Dual detection of fungal infections in Drosophila via recognition of glucans and sensing of virulence factors. Cell 2006, 127, 1425-1437.

85. Tanaka, H.; Yamakawa, M. Regulation of the innate immune responses in the silkworm, Bombyx mori. Invertebrate Surviv. J. 2011, 8, 59-69.

86. Dunn, P.E.; Dai, W.; Kanost, M.R.; Geng, C. Soluble peptidoglycan fragments stimulate antibacterial protein synthesis by fat body from larvae of Manduca sexta. Dev. Comp. Immunol. 1985, 9, 559-568.

87. Kanost, M.R.; Dai, W.; Dunn, P.E. Peptidoglycan fragments elicit antibacterial protein synthesis in larvae of Manduca sexta. Arch. Insect Biochem. Physiol. 1988, 8, 147-164.

88. Iketani, M.; Morishima, I. Induction of antibacterial protein synthesis by soluble peptidoglycan in isolated fat body from larvae of the silkworm, Bombyx mori. Insect Biochem. Mol. Biol. 1993, 23, 913-917.

89. Morishima, I.; Horiba, T.; Iketani, M.; Nishioka, E.; Yamano, Y. Parallel induction of cecropin and lysozyme in larvae of the silkworm, Bombyx mori. Dev. Comp. Immunol. 1995, 19, 357-363. 
90. Rao, X.-J.; Yu, X.-Q. Lipoteichoic acid and lipopolysaccharide can activate antimicrobial peptide expression in the tobacco hornworm Manduca sexta. Dev. Comp. Immunol. 2010, 34, 1119-1128.

91. Ochiai, M.; Ashida, M. A pattern recognition protein for peptidoglycan. J. Biol. Chem. 1999, 274, 11854-11858.

92. Seitz, V.; Clermont, A.; Wedde, M.; Hummel, M.; Vilcinskas, A.; Schlatterer, K.; Podsiadlowski, L. Identification of immunorelevant genes from greater wax moth (Galleria mellonella) by a subtractive hybridization approach. Dev. Comp. Immunol. 2003, 27, 207-215.

93. Onoe, H.; Matsumoto, A.; Hashimoto, K.; Yamano, Y.; Morishima, I. Peptidoglycan recognition protein (PGRP) from eri-silkworm, Samia cynthia ricini; protein purification and induction of the gene expression. Comp. Biochem. Physiol. 2007, 147, 512-519.

94. Eum, J.H.; Seo, Y.R.; Yoe, S.M.; Kang, S.W.; Han, S.S. Analysis of the immune-inducible genes of Plutella xylostella using expressed sequence tags and cDNA microarray. Dev. Comp. Immunol. 2007, 31, 1107-1120.

95. Hughes, A.L. Evolution of the $\beta \mathrm{GRP} / \mathrm{GNBP} / \beta-1,3$-glucanase family of insects. Immunogenetics 2012, 64, 549-558.

96. Kaneko, T.; Goldman, W.E.; Mellroth, P.; Steiner, H.; Fukase, K.; Kusumoto, S.; Harley, W.; Fox, A.; Golenbock, D.; Silverman, N. Monomeric and polymeric gram-negative peptidoglycan but not purified LPS stimulate the Drosophila IMD pathway. Immunity 2004, 20, 637-649.

97. Tanaka, H.; Sagisaka, A.; Fujita, K.; Kaneko, Y.; Imanishi, S.; Yamakawa, M. Lipopolysaccharide elicits expression of immune-related genes in the silkworm, Bombyx mori. Insect Mol. Biol. 2009, 18, 71-75.

98. Ao, J.; Ling, E.; Yu, X.-Q. Drosophila C-type lectins enhance cellular encapsulation. Mol. Immunol. 2007, 44, 2541-2548.

99. Watanabe, A.; Miyazawa, S.; Kitami, M.; Tabunoki, H.; Ueda, K.; Sato, R. Characterization of a novel C-type lectin, Bombyx mori multibinding protein, from the B. mori hemolymph: Mechanism of wide-range microorganism recognition and role in immunity. J. Immunol. 2006, 177, 4594-4604.

100. Koizumi, N.; Imai, Y.; Morozumi, A.; Imamura, M.; Kadotani, T.; Yaoi, K.; Iwahana, H.; Sato, R. Lipopolysaccharide-binding protein of Bombyx mori participates in a hemocyte-mediated defense reaction against Gram-negative bacteria. J. Insect Physiol. 1999, 45, 853-859.

101. Yu, X.Q.; Gan, H.; Kanost, M.R. Immulectin, an inducible C-type lectin from an insect, Manduca sexta, stimulates activation of plasma prophenoloxidase. Insect Biochem. Mol. Biol. 1999, 29, 585-597.

102. Yu, X.Q.; Kanost, M.R. Immulectin-2, a lipopolysaccharide-specific lectin from an insect, Manduca sexta, is induced in response to Gram-negative bacteria. J. Biol. Chem. 2000, 275, 37373-37381.

103. Yu, X.-Q.; Tracy, M.E.; Ling, E.; Scholz, F.R.; Trenczek, T. A novel C-type immulectin-3 from Manduca sexta is translocated from hemolymph into the cytoplasm of hemocytes. Insect Biochem. Mol. Biol. 2005, 35, 285-295.

104. Yu, X.-Q.; Ling, E.; Tracy, M.E.; Zhu, Y. Immulectin-4 from the tobacco hornworm Manduca sexta binds to lipopolysaccharide and lipoteichoic acid. Insect Mol. Biol. 2006, 15, 119-128. 
105. Jiang, H.; Ma, C.; Lu, Z.-Q.; Kanost, M.R. $\beta-1,3-$ Glucan recognition protein-2 ( $\beta$ GRP-2) from Manduca sexta: An acute-phase protein that binds $\beta$-1,3-glucan and lipoteichoic acid to aggregate fungi and bacteria and stimulate prophenoloxidase activation. Insect Biochem. Mol. Biol. 2004, 34, 89-100.

106. Wang, Y.; Jiang, H. Interaction of $\beta$-1,3-glucan with its recognition protein activates hemolymph proteinase 14, an initiation enzyme of the prophenoloxidase activation system in Manduca sexta. J. Biol. Chem. 2006, 281, 9271-9278.

107. Ashok, Y. Drosophila Toll pathway: The new model. Sci. Signal. 2009, 2, 1-2.

108. Hetru, C.; Hoffmann, J.A. NF-kappaB in the immune response of Drosophila. Cold Spring Harb. Perspect. Biol. 2009, 1, 1-15.

109. Michel, T.; Reichhart, J.M.; Hoffmann, J.A.; Royet, J. Drosophila Toll is activated by Grampositive bacteria through a circulating peptidoglycan recognition protein. Nature 2001, 414, $756-759$.

110. El Chamy, L.; Leclerc, V.; Caldelari, I.; Reichhart, J.-M. Sensing of "danger signals" and pathogen-associated molecular patterns defines binary signaling pathways "upstream" of Toll. Nat. Immunol. 2008, 9, 1165-1170.

111. Piao, S.; Song, Y.-L.; Kim, J.H.; Park, S.Y.; Park, J.W.; Lee, B.L.; Oh, B.-H.; Ha, N.-C. Crystal structure of a clip-domain serine protease and functional roles of the clip domains. EMBO J. 2005, 24, 4404-4414.

112. Jang, I.-H.; Chosa, N.; Kim, S.-H.; Nam, H.-J.; Lemaitre, B.; Ochiai, M.; Kambris, Z.; Brun, S.; Hashimoto, C.; Ashida, M.; et al. A Spätzle-processing enzyme required for toll signaling activation in Drosophila innate immunity. Dev. Cell 2006, 10, 45-55.

113. Valanne, S.; Wang, J.-H.; Rämet, M. The Drosophila Toll signaling pathway. J. Immunol. 2011, 186, 649-656.

114. Jiang, H.; Vilcinskas, A.; Kanost, M.R. Immunity in lepidopteran insects. In Invertebrate Immunity; Söderhäll, K., Ed.; Springer: New York, NY, USA, 2010; pp. 181-204.

115. Ao, J.; Ling, E.; Yu, X.-Q. A Toll receptor from Manduca sexta is in response to Escherichia coli infection. Mol. Immunol. 2008, 45, 543-552.

116. An, C.; Jiang, H.; Kanost, M.R. Proteolytic activation and function of the cytokine Spätzle in the innate immune response of a lepidopteran insect, Manduca sexta. FEBS J. 2010, 277, 148-162.

117. Wang, Y.; Cheng, T.; Rayaprolu, S.; Zou, Z.; Xia, Q.; Xiang, Z.; Jiang, H. Proteolytic activation of pro-Spätzle is required for the induced transcription of antimicrobial peptide genes in lepidopteran insects. Dev. Comp. Immunol. 2007, 31, 1002-1012.

118. Zhong, X.; Xu, X.-X.; Yi, H.-Y.; Lin, C.; Yu, X.-Q. A Toll-Spätzle pathway in the tobacco hornworm, Manduca sexta. Insect Biochem. Mol. Biol. 2012, 42, 514-524.

119. An, C.; Ishibashi, J.; Ragan, E.J.; Jiang, H.; Kanost, M.R. Functions of Manduca sexta hemolymph proteinases HP6 and HP8 in two innate immune pathways. J. Biol. Chem. 2009, 284, 19716-19726.

120. Gertz, E.M.; Yu, Y.-K.; Agarwala, R.; Schäffer, A.A.; Altschul, S.F. Composition-based statistics and translated nucleotide searches: Improving the TBLASTN module of BLAST. BMC Biol. 2006, 4, 41-54. 
121. Sievers, F.; Wilm, A.; Dineen, D.; Gibson, T.J.; Karplus, K.; Li, W.; Lopez, R.; McWilliam, H.; Remmert, M.; Söding, J.; et al. Fast, scalable generation of high-quality protein multiple sequence alignments using Clustal Omega. Mol. Syst. Biol. 2011, 7, 1-6.

122. Goujon, M.; McWilliam, H.; Li, W.; Valentin, F.; Squizzato, S.; Paern, J.; Lopez, R. A new bioinformatics analysis tools framework at EMBL-EBI. Nucleic Acids Res. 2010, 38, 695-699.

123. Felsenstein, J. PHYLIP-Phylogeny Inference Package (Version 3.2). Cladistics 1989, 5, 164-166.

124. Gilbert, D. Phylodendron version $0.8 \mathrm{~d}$ beta. Available online: http://iubio.bio.indiana.edu/ treeapp/ (accessed on 26 May 2013).

125. Choe, K.-M.; Lee, H.; Anderson, K.V. Drosophila peptidoglycan recognition protein LC (PGRPLC) acts as a signal-transducing innate immune receptor. Proc. Natl. Acad. Sci. USA 2005, 102, 1122-1126.

126. Schmidt, R.L.; Trejo, T.R.; Plummer, T.B.; Platt, J.L.; Tang, A.H. Infection-induced proteolysis of PGRP-LC controls the IMD activation and melanization cascades in Drosophila. FASEB J. 2008, 22, 918-929.

127. Kaneko, T.; Yano, T.; Aggarwal, K.; Lim, J.-H.; Ueda, K.; Oshima, Y.; Peach, C.; ErturkHasdemir, D.; Goldman, W.E.; Oh, B.-H.; et al. PGRP-LC and PGRP-LE have essential yet distinct functions in the Drosophila immune response to monomeric DAP-type peptidoglycan. Nat. Immunol. 2006, 7, 715-723.

128. Takehana, A.; Yano, T.; Mita, S.; Kotani, A.; Oshima, Y.; Kurata, S. Peptidoglycan recognition protein (PGRP)-LE and PGRP-LC act synergistically in Drosophila immunity. EMBO J. 2004, 23, 4690-4700.

129. Leulier, F.; Vidal, S.; Saigo, K.; Ueda, R.; Lemaitre, B. Inducible expression of double-stranded RNA reveals a role for dFADD in the regulation of the antibacterial response in Drosophila adults. Curr. Biol. 2002, 12, 996-1000.

130. Leulier, F.; Rodriguez, A.; Khush, R.S.; Abrams, J.M.; Lemaitre, B. The Drosophila caspase Dredd is required to resist Gram-negative bacterial infection. EMBO Rep. 2000, 1, 353-358.

131. Valanne, S.; Kallio, J.; Kleino, A.; Rämet, M. Large-scale RNAi screens add both clarity and complexity to Drosophila NF-кB signaling. Dev. Comp. Immunol. 2012, 37, 9-18.

132. Kleino, A.; Valanne, S.; Ulvila, J.; Kallio, J.; Myllymäki, H.; Enwald, H.; Stöven, S.; Poidevin, M.; Ueda, R.; Hultmark, D.; et al. Inhibitor of apoptosis 2 and TAK1-binding protein are components of the Drosophila Imd pathway. EMBO J. 2005, 24, 3423-3434.

133. Zhuang, Z.-H.; Sun, L.; Kong, L.; Hu, J.-H.; Yu, M.-C.; Reinach, P.; Zang, J.-W.; Ge, B.-X. Drosophila TAB2 is required for the immune activation of JNK and NF-kappaB. Cell. Signal. 2006, 18, 964-970.

134. Gesellchen, V.; Kuttenkeuler, D.; Steckel, M.; Pelte, N.; Boutros, M. An RNA interference screen identifies Inhibitor of Apoptosis Protein 2 as a regulator of innate immune signalling in Drosophila. EMBO Rep. 2005, 6, 979-984.

135. Valanne, S.; Kleino, A.; Myllymäki, H.; Vuoristo, J.; Rämet, M. Iap2 is required for a sustained response in the Drosophila Imd pathway. Dev. Comp. Immunol. 2007, 31, 991-1001. 
136. Kleino, A.; Myllymäki, H.; Kallio, J.; Vanha-aho, L.-M.; Oksanen, K.; Ulvila, J.; Hultmark, D.; Valanne, S.; Rämet, M. Pirk is a negative regulator of the Drosophila Imd pathway. J. Immunol. 2008, 180, 5413-5422.

137. Cheng, T.-C.; Zhang, Y.-L.; Liu, C.; Xu, P.-Z.; Gao, Z.-H.; Xia, Q.-Y.; Xiang, Z.-H. Identification and analysis of Toll-related genes in the domesticated silkworm, Bombyx mori. Dev. Comp. Immunol. 2008, 32, 464-475.

138. Park, J.-A.; Kim, Y. Eicosanoid biosynthesis is activated via Toll, but not Imd signal pathway in response to fungal infection. J. Invertebr. Pathol. 2012, 110, 382-388.

139. Johnson, J.A.; Bitra, K.; Zhang, S.; Wang, L.; Lynn, D.E.; Strand, M.R. The UGA-CiE1 cell line from Chrysodeixis includens exhibits characteristics of granulocytes and is permissive to infection by two viruses. Insect Biochem. Mol. Biol. 2010, 40, 394-404.

(C) 2013 by the authors; licensee MDPI, Basel, Switzerland. This article is an open access article distributed under the terms and conditions of the Creative Commons Attribution license (http://creativecommons.org/licenses/by/3.0/). 